\section{THE 2005 YEAR'S WORK IN LINGUISTICS IN THAILAND}

\section{Pranee Kullavanijaya ${ }^{1}$}

\section{Abstract}

A study of Thai linguistics works in 2005 shows that most are M.A. theses and doctoral dissertations done by Thai students in five universities in Thailand and a few universities in the U.S.. and the U.K.. Only three works analyse foreign languages, while the rest investigate the Bangkok Thai dialect. Five main areas are identified: sound and orthography, sociolinguistics, utterance semantics, lexical semantics and syntax-semantic interface. More works focus on the last two areas. With regard to the frameworks used in the analyses, pragmatics, discourse, and speech acts are found most often. Several topics such as village names, politeness, and slang, which have been studied previously, were investigated again in 2005 with different locations or different groups of speakers. Although

${ }^{1}$ Emeritus Professor, Department of Linguistics, Faculty of Arts, Chulalongkorn University, Bangkok, Thailand. such investigations may yield additional information on the topics, new questions or new probes into similar data may be preferable.

\section{Introduction}

The year's work in linguistics in Thailand for 2005 is intended to give an overview of linguistics studies and reveal research directions and significant contributions by Thai scholars in this field.

The works studied were collected with the help of three former Ph.D students ${ }^{2}$ in linguistics in the Department of Linguistics, Chulalongkorn University, from three main sources: university websites, academic journals, and university libraries. The titles of the works and abstracts were gathered first, after which the full texts were read, if available, and a summary of each was written. It was found that almost all the relevant research was produced by linguistics graduates at the Master's and doctoral levels from five universities in Thailand: Chulalongkorn,

\footnotetext{
${ }^{2}$ They are Dr. Phinnarat Akharawatthanakun, Dr. Nunghatai Rangponsumrit, and Dr. Phanintra Teeranon.
} 
Thammasat, Kasetsart, Mahidol, and Prince of Songkhla.

It must be noted from the beginning that despite our attempt, we could not acquire some works, especially dissertations produced at universities abroad. We also excluded some of them from our study if the abstracts were unclear. However, we still put these works in our references so that their contributions can be recognized and studied later if so desired.

Compared to several other fields in the humanities, researchers in general linguistics and in Thai linguistics are more active in contributing to the field. Although some papers are not based on full research in a strict sense, they ask interesting questions and provide some answers which may inspire deep and full studies later.

Most of the works studied were written in Thai, with abstracts written in English. This practice limits the exchange of ideas with linguists who do not read Thai. This

\footnotetext{
${ }^{3}$ Several linguistics works were also produced by graduates from the Thai departments of these five universities in Thailand, as well as from universities abroad, especially from U.S. universities.
}

"Year's Work" is an attempt to overcoms this problem to a certain extent.

\section{Works on Sounds and}

\section{Orthography}

Linguistics works from 2005 may be grouped into five main areas: sound and orthography, lexical semantics, syntaxsemantics interface, utterance semantics, and socio-linguistics. These areas are discussed in turn below.

Works in the area of sounds can be further sub-divided. The first sub-division touches on the controversial topic of the gap between spelling and pronunciation. Two papers by members of the Royal Thai Institute, Nacaskul and Dejnakarintra commented on "Thaiization" or the representation of English loan words in Thai written forms. The rules of "Thaiization" given by the Royal Thai Institute do not correspond well with the common pronunciations of some English loanwords. The Thai written forms "โิกก" for "Coke" and "เต็นท์" for "tent" must be pronounced as / khôok/ and /ten/ according to the Thai orthographic system, not 
Khook/ and /tén/ which are the common

monounciations. Nacaskul proposed that the Royal Thai Institute be aware of the common pronunciation of English loan words in Thai and that the Institute reconsider the use of tone markers and the

" marker in the spelling of loanwords so

as to avoid unnecessary confusion between spelling and pronunciation.

Another three papers, by Kanjanavan and Bhandhumedha, deal with the transcribing of vowel length in dead syllables and the inconsistency in spelling as a result of the Thai accentual system. In one of her two papers, Kanjanavan observed that there are several ways to write Thai words in English. For example, the proper name วันเพ็ญ" can be transcribed as [wanphen], romanized as "Wanphen", or built up syllable by syllable substituting English words with the same sound, as "onepen". In her other paper, Kanjanavan proposed using the tone marker, majeek, ( ' ), to shorten a long closed syllable, as แซด > แซ่ด, or using “ ะ " to mark an already short syllable, as เซต > เซ็ต. In both types of syllables, there is no tonal problem of the kind mentioned by Nacaskul. The proposal only serves to make the shortening of the vowels clearer. This proposal is arguable because, in words where length is not phonemic, the speakers have the option of lengthening or shortening vowel length and they usually know when to shorten or lengthen vowels without any markers. Bhandhumedha (2005) used the accentual system in Thai to explain vowel reduction in the first syllable of some Thai words and the various pronunciations of Pali-Sanskrit loanwords in Thai, including newly coined Thai words.

Two papers dealing with the way in which vowels illustrate the cognitive processes of Thai speakers constitute the second subdivision of works on sound. The first, by Tuaycharoen, is on the relation between vowel gradation and semantic implication in Isaan-dialect doublets. For example, unrounded low front vowels implied wide open space, extended site, or ugly big size. Another paper, by Awirutthiyothin, examines the cognitive process of Thai speakers in Thai word games in which there are certain patterns of addition, reduction, reordering, and substitution of 
vowel sounds. These patterns are naturally recognized by Thai children.

The third sub-division in the area of sounds includes works in acoustic and auditory phonetics. These include three dissertations done at American universities and to Chulalongkorn University. Kallayanamit's "Intonation in Standard Thai: Contours, Registers and Boundary Tones" gave acoustic information for six nine-syllable utterances in seven different contexts, such as yes-no questions and requests. This information can be of some use to soundsynthesis research. Teeranon worked acoustically on three Waic dialects to see the extent to which vowels, initial consonants, final consonants, or a combination thereof influence pitch, and to see which of these influences were likely to cause pitches to develop into tonemes. Acoustic work by Onsuwan on temporal relations between consonants and vowels in Thai syllables analysed the perception of time duration of consonants and vowels in certain types of syllables. Again, the information produced by this work should benefit ongoing research on sound synthesis in Thai. The last work in this sub-area, by Meesiangsri, is an interesting application of acoustic phonetics (through a computerized speech lab) and auditory judgement to set up speech patterns in the political debates of a Thai politician. She also analyzed body movements and gestures that accompanied these set speech patterns.

This linguistic work on sound in 2005 indicates substantial interest in acoustic phonetics. This is probably due to the availability of computer programs for acoustic analysis which help young researchers to feel confident in their analyses. However, it must be realized that the significant contribution lies not in the computerized results but in the ability to interpret the results, for which deeper discussion should be encouraged.

\section{Works in lexical semantics}

A number of linguistic works in 2005 were in the area of lexical semantics. In general, they dealt with specific sets of words, such as color terms, village names, and teenagers' slang. Structural analyses of these sets of words were conducted, producing findings that only served to confirm the structural patterns of the words and/or the devices used to form the 
words that were given in earlier research ${ }^{4}$. A cognitive approach was used, however, used in a few works.

Two studies of village names by Jiranantanapon and Singhnoi and by Lertchaiworakul, reveal similar structures of village names, with head nouns followed by modifying words. Compounding and doublets are also used. These findings are consistent with the earlier research findings of the lexical structures of village names in other areas in Thailand.

Studies of teenagers' slang by Sukmuen and Banditpak; slogans in television advertisements by Kasemsuwan, and language in radio advertisements by Antarasena et al. had similar objectives: analyzing the structure of the constructions and finding devices that form the constructions. The common devices include syllable clipping, synonymous doublets, word borrowings, rhyming and new coinage. To understand Thai riddles, Thima claims that certain presupposed information is required. To make riddles

4 See, for example, Somsong Burusphat et al., The Status of Research in Linguistic in Thailand (2506-2536). and also to understand them, an ability to use synonyms, antonyms, homographemes, word puns, and words from the same semantic paradigm is necessary. In analyzing food names, Kormitin applied the cognitive approach in addition to describing them structurally. The use of metaphor in food names either partially or completely reflects not only the ingredients of the dishes but also the belief and wish that the dishes may bring good health.

\section{Works on the syntax-semantics interface}

Classification of word categories and grammatical categories usually requires the use of syntax-semantics analysis. In analyzing classifiers in Thai, Jaturongkachoke (2005) argued that the cognitive approach could explain why the same classifiers are used for nouns signifying entirely different shapes. Shapes or sizes of the entities are therefore not the criteria used to groups nouns, as previously claimed. Rather, she argued, the use of the entities determined the grouping. Unfortunately, the explanation of the classifier /baj/ she used as an example may raise some doubts. The 
explanation that /baj/ is used for container nouns such as glasses, boxes, or plates, is well accepted, but to say that this use is an extension of /baj/, a classifier for flat things such as leaves, is doubtful. One may argue that /baj/ for flat things is more recent and is probably derived from the repetition of the first syllable in /baj maj/ "leaf". Repetition of a noun as a classifier is not uncommon, and it is usually recognized as a recent classifier formation.

Aspect was once a topic hardly touched on seriously by Thai researchers. Recently, however, more serious work has been done on this topic since Boonyapatipark (1983), Sookgasem (1990), and Kullavanijaya and Bisang (2004). In 2005, two studies were produced in connection with aspect in Thai. Koenig and Muansuwan's "The Syntax of Aspect in Thai" (2005) studied whether the semantic structure of aspect in Thai was isomorphic to the syntactic structure. They concluded that the two structures were of different levels and were interindependent. The other research was a Master's thesis by Tansiri entitled "Interactions between Grammatical Aspect and Lexical Aspect: A Case Study of Alternating Intransitive Constructions in Thai" (2005). Six lexical aspect classes were identified for alternating intransitive constructions: transitory state, inherent state, activity, accomplishment, achievement, and semelfactive. Three aspect markers, /léew/, /kamlan/ and /yùu/ were studied with regard to their occurrences in the aforementioned six classes of aspect.

In addition, epistemic modality in Thai was studied by Rangkupan in both syntactic and semantic aspects. Syntactically, epistemic modality is expressed by four types of epistemic markers: preverbal auxiliaries, sentence beginning particles, sentence final particles, and adverbs. Semantically, five types of epistemic meaning are identified: speculative, deductive, assumptive, dubitative and certainty.

\section{Utterance semantics}

Utterance semantics is a covering term used for works focusing on the level of the sentence and above. Most of the works at this level employ a pragmatic approach or a discourse analysis framework; hence the term semantics in "Utterance semantics". 
The first group of works considered under this heading includes research, theses, or dissertations analyzing particular types of language usage, such as political head news, travelogues, and web-board language. Usually, the works in this group give a descriptive analysis. Chittaprasartsin's thesis, entitled "Some Linguistic Aspects of Thai Law: The Criminal Code and the Civil and Commercial Code" shows that Thai legal language predominantly uses compound and complex constructions rather than simple sentences. Modifying units are generally added to help clarify the utterances. Regarding the reference process, the second person personal pronoun /thâan/ is widely used, as are demonstratives. Studying Thai travelogues, Burusphat used a text-analysis framework. She analyzed the role of time adverbial clauses and identified six functions that they perform in travelogues. For example, one function is to signal that the texts are travelogues; another function is to mark or highlight certain events in a paragraph. Another description of a particular type of language appears in a paper by Sittirak et al. This paper studies language used in translating sports news. It is found that not only words or phrases with exaggerating meanings are used in sports news but also doublets, clipped words, and polysemes, together with special letterings, are employed to create interest and add an entertaining tone to the news. It is also found that it was not necessary to adhere to the original sports news when translating. Adapting of content is found, and even rewriting from various news sources is practiced.

Another work describing a particular type of language is Jaroenkiatboworn's dissertation entitled "A Discourse Analysis of Jokes in Thai". She showed that discourse is one of the two important devices used in telling jokes. The other device is, as can be predicted, the use of words to create ambiguity or trick the auditor into an incorrect or unusual interpretation. The dissertation pointed out that people in a community usually assume a set of characteristics for a certain group of people; for example, politicians are assumed to have the characteristics of being crooked, unreliable, and rather foolish. Such set ideas form the basis for joke making.

Pongudom also chose a discourse approach in analyzing cosmetics advertisements in two Thai magazines. She discovered two 
devices. The first one is lexical semantics: using verbs meaning "beauty" modified by adverbs to intensify a beauty state. The other device exercises pragmatic and discourse roles such as factual statements, opinions from users, leading questions, and metaphors and similes in connection with "beauty". Setting up standards of "being beautiful", such as "Only perfect beauty counts" or "Western beauty is in fashion and can only be achieved through cosmetics", is generally used. The last work in the area of discourse is a paper by Richard Watson Todd entitled "A Fuzzy Approach to Discourse Topics". In order to determine topics in a discourse precisely, he claimed that eclectic approaches were necessary. Six approaches were given: theme-rheme progression, given-new progression, speech act analysis, Hoey's lexical analysis, topic-based analysis, and association-based networks of concepts.

Language used in internet chatrooms and web-boards has become a topic of interest. In 2005, two papers dealt with language in these contexts. Panyametheekul analyzed the language used in internet chatrooms and revealed the outline of the chat. There are, according to her, the beginning part, in which the chatters introduce themselves to each other, the middle part, in which they begin to chat, and the ending, where arrangements for the next chat are made. In the first two parts, various orthographic and language devices are used to impress the partner and to induce the partner to continue chatting. The orthographic devices show the attempt to create a virtual conversation and foster a sense of intimacy. Examples of the orthographic devices given in the paper are the repetition of the last letter in a word such as ควายยยยยย or the choice of informal speaking words, such as ก่า for กว่า. Panyametheekul observed that language used in the chatrooms might influence Thai language later on. Certainly, the language in the chatrooms has already influenced written Thai and this calls for further study. Maneechuket gave another way of looking at web-board language. Using Gricean maxims as a framework, she pointed out that conversations on web-boards or elsewhere call for respecting the conversational maxims to maintain a happy conversation. Polite language forms and hedging are among the conversational devices examined in the paper. Another work on web-board language was a thesis by Worapong. Worapong studied the web- 
board language of secondary-school students. Her analysis was restricted to the word level. She showed that words in the web-board were misspelt and clipped or abbreviated, and that borrowed words, slang, onomatopoeic words, reduplicatives, and word puns were commonly used by secondary-school students.

Another popular topic in the linguistic work of 2005 is related to speech acts and Levinson's politeness and indirectness strategies. Beginning with Wilaiwan Khanittanan, who provided a diachronic picture of linguistic politeness in Thai from the Sukhothai period to the Ratanakosin period on the basis of the development of court language and terms of address, and moving on to Hongladarom and Hongladarom's study on "Politeness in Thai Computer-Mediated Communication", in which Internet politeness was studied, one can see politeness roles in the Thai ways of living and also how much the topic of linguistic politeness has initiated various aspects of study in Thailand. In 2005 , there are, in addition to the two papers aforementioned, the following works: "The Significance of 'Face' and Politeness in Social Interaction Revealed through Their 'Face Idioms' by Magaret
Ukosakul and "Indirectness as a Politeness Strategy of Thai Speakers" by Deeyu Srinarawat. Several theses and dissertations have been and are being done in this area, and it is probably time for a "state of the art" review of politeness in Thai to be conducted.

\section{Works in the Socio-linguistic} Area

Works in the socio-linguistic area in 2005 consisted of two dissertations and two theses. Of these, language contact was a main issue discussed in three of the four works. The dissertation by Praparat Prompapakorn, entitled "Dialect Contact and New Dialect Formation in a New Thai Town" was particularly interesting. It seemed to open a new horizon on linguistic research in Thailand. Praparat claimed that residents in Baan Khlong Sathorn Community, who are speakers of the central Thai dialect, the Khorat dialect, and the Isaan Laotian dialect, have gone through a process of koineisation and developed a new koine dialect for the community. This challenges an attestation and also encourages a search for other koines in Thailand. 
Two works on code-switching and codemixing examine the contact between English and Thai. Chuliporn Suaysod analysed the speech of secondary-school students and found that the students used English words in their utterances. These included full English loanwords, abbreviated English loanwords, English words with Thai doublets and new coinages. She pointed out that female students used more English words in their speech then male students and that students in higher secondary education also had a tendency to use more English loanwords. The other work was a dissertation on "Thai-English Code Switching: a Hawai'i Case Study" by Sumittra Suraratdecha. Her findings revealed that comparing two sociolinguistic models, markeness model and conversational code-switching approach, the latter was more applicable to her case study. At the syntactic level, she found that code-switching across sentences was rare. Also, code- switching was used among intimates. She concluded that social factors determined code-switching patterns and the language forms used. The last work in the socio-linguistic area was Kittiwan Tepnarong's thesis on linguistic features and attitudes towards language used in the political headlines of daily newspapers. Besides giving a description of the types of words used in the headlines, the thesis also points out the significance of education in understanding the headlines, which contain many abbreviations and clipped words.

\section{Other types of work}

The remaining works from 2005 cover a variety of topics. Two theses deserve special mention. These dealt with computational linguistics. Both consisted of experimental research designed to discover the best method and effective rules for identifying or recognizing and classifying certain types of words. Surudee Chattraimongkon worked on the recognition of entity names and Akraphon Ekwonganan on loanwords and Thai native words. However, despite these two works, research on computational linguistics is still much lacking.

\section{Comments}

The linguistic research in 2005 studied above shows that almost all the research performed by Thai scholars and graduates concentrated on standard Thai dialect or Bangkok Thai. However, there were three works that analysed foreign languages. They 
were the dissertations on "Morphological and Analytic Causatives in Spanish" by Nunghatai Rangpongsumrit, "A Study of Color Terms in Thai and Vietnamese" by Rujiwan Laophairoj, and "Politeness in Korean" by Prajuab Yimsen. I predict that more work will be done on foreign languages in the future since more graduate programs are now being offered in many foreign languages, such as Chinese, Japanese, French, German, and Cambodian. Also, research on typology is beginning to receive more interest in the country.

Also, more linguistic research has recently been done in the areas of pragmatics, discourse, speech acts, and sociolinguistics, rather than in core areas such as formal syntax or phonetics. This trend seemingly makes linguistics more applicable and more understandable to the public in general. Yet general research practice still focuses on analyses of language in different locations or of different groups of speakers using the same frameworks and the same question as, and with findings that only confirm, earlier research. New questions or new probes into similar data are to be desired.

\section{References}

Antarasena, Sirilak, et al. 2005. Language

Use in the Radio Advertisements

Nominated in the Pre-Final

Selectionfor TACT Awards during 1997-2000. Sonklanakarin: Journal of Social Sciences and Humanities Division of Academic Affairs, PSU 11.2: 165-183.

Awirutthiyothin, Tamjai. 2005a. Language Play. Sonklanakarin: Journal of Social Sciences and Humanities Division of Academic Affairs, PSU 11.3: 335-339. 2005b. Kaan Tangchue Kaan Len Thaang Phasaa Khong Khon Thai (Thai Word Game Naming). Journal of Social Sciences and Humanities Division of Academic Affairs, PSU 1.1: $36-45$.

Banditpak, Thanisorn. 2005: A Study of Thai Slang in Teenagers Found in Entertainment Magazines, Master's thesis, Kasetsart University, Bangkok, Thailand.

Bhandhumedha, Navavan. 2005. Siang

Nak Baw Kap Khamthaam Kiaw

Kap Kham Naj Phasaa Thaj

(Accentual System and Questions on Word Pronunciation in Thai). 
The Royal Thai Institute Journal. 30.3: $742-753$

Boonyapatipark, Tasanalai. 1983. A Study

of Aspect in Thai. Doctoral

dissertation, University of London.

Burusphat, Somsong. 2005. The Textual

Functions of Time Adverbial Clauses

in Thai Travelogues. Manusya:

Journal of Humanities 8.1: 1-21.

Burusphat, Somsong et al. 1997. The

Status of Research in Linguistics

in Thailand, A Research Report to

the National Research Council of

Thailand for the Fiscal Year 1994.

Chattraimongkol, Surudee. 2005. Named

Entity Recognition and Classification

in Thai. Mater's thesis, Chulalongkorn

University, Bangkok, Thailand.

Chittaprasartsin, Pimpa. 2005. Some

Linguistic Aspects of Thai Law: The

Criminal Code and the Civil and

Commercial Code. Master's thesis,

Thammasat University, Bangkok,

Thailand.

Dejnakarintra, Mongkol. 2005. Khor Sangket

Bang Prakaan Kiawkap Lak Kaan

Banjat Sap (Some Observations in

Connection to Word Coinage). The

Royal Thai Institute Journal. 30.1:

$39-57$.
Ekwonganan, Akarapol. 2005. Identification

of Thai and Transliterated Words by

N-Gram Models. Master's thesis,

Chulalongkorn University, Bangkok,

Thailand.

Hongladarom, Krisadawan, and Soraj

Hongladarom. 2005. Politeness in Thai

Computer-Mediated Communication.

In Broading the Horizon of Linguistic

Politeness, ed. by Robin Tolmach

Lakoff and Sachiko Ide, pp. 269-292.

Amsterdam: John Benjamins.

Jaroenkiatboworn, Kanjana. 2005. A

Discourse Analysis of Jokes in Thai.

Doctoral dissertation, Chulalongkom

University, Bangkok, Thailand.

Jaturongkachoke, Ketkanda. 2005. A Closer

Look at the Thai Classifier System.

Journal of Liberal Arts, Ubon

Ratchathani University 2.1:115-142.

Jiranantanapon, Supattra and Unchalee

Singnoi. 2005a. Toponyms (Village

Names) in the Lower Northern Part

of Thailand, Phitsanulok Province.

Journal of Language and Linguistics,

Thammasat University 24.1: 75-94.

2005b. Toponyms (Village Names)

in the Lower Northern Part of

Thailand, Uttaradit Province. Journal

of Humanities, Naresuan University

2.1: $29-44$. 
Kallayanamit, Saovapak. 2005. Intonation in

Standard Thai: Contours, Registers

and Boundary Tones. Doctoral

dissertation, Georgetown University,

Washington,DC.

Kanjanavan, Nittaya, 2005a. Tua Khian Kap

Siang Aan (Spelling and

Pronunciation). The Royal Thai

Institute Journal. 30.2: 44-58.

.2005b, Akkarawithii Thii Khuan

Plian Lae Mai Khuan Plian

(Orthographic Systems Which

Should and Should Not Be Modified).

The Royal Thai Institute Journal. 30.4:

1048-1054.

Kasemsuwan, Porntipar. 2005. A Linguistic

Analysis of Advertisement Slogans

on Television. Master's thesis,

Kasetsart University, Bangkok,

Thailand.

Khanittanan, Wilaiwan. 2005. An Aspect of

the Origins and Development of

Linguistic Politeness in Thai. In

Broading the Horizon of Linguistic

Politeness, ed. by Robin Tolmach

Lakoff, and Sachiko Ide, pp. 315-

335. Amsterdam: John Benjamins.

Koenig, Jean-Pièrre, and Nuttanart

Muansuwan. 2005. The Syntax of

Aspect in Thai. In Natural Language

and Linguistic Theory. 232: 335-380.
Kormitin, Anattaya. 2005. A Cognitive

Semantics Study of Food Naming in

Thai. Master's thesis, Thammasat

University, Bangkok, Thailand.

Kullavanijaya, Pranee, and Walter Bisang.

2004. Another Look at Aspect in

Thai. Paper presented at the SEAL

XIII Conference, 19-21 May 2004,

Bangkok., Thailand.

Laophairoj, Rujiwan. 2005. A Comparison of

Thai and Vietnamese Color Terms.

Master's thesis, Mahidol University,

Bangkok, Thailand.

Lertchaiworakul, Nareerat. 2005. A

Comparison of Village Naming in

Thailand. Master's thesis, Thammasat

University, Bangkok, Thailand.

Maneechuket, Siriporn. 2005. Wajana

Patibatsart Kap Pharadornraphap:

Kaan Chaj Phasaa Naj Kradaan

Khaaw (Pragmatics and Brotherhood:

Language Use on Web-board).

Journal of Humanities, Naresuan

University. 2.1: 15-28.

Meesiangsri, Nawaporn. 2004. A Linguistic

and Rhetorical Analysis of Chuan

Leekpai's Style of Political Oratory.

Master's thesis, Thammasat

University, Bangkok, Thailand.

Nacaskul, Karnchana. 2005. Kaan Thapsap

Kap Rabop Akharawithii Thaj 
(Transliteration and Thai

Orthographic System). The Royal

Thai Institute Journal. 30.2: 554-562

Onsuwan, Chutamanee. 2005. Temporal

Relations between Consonants and

Vowels in Thai Syllables. Doctoral

dissertation, University of Michigan,

U.S.A.

Panyametheekul, Siriphorn. 2005. Phasaa Naj

Hong Sonthana Thaang Internet

(Language in Internet Chatroom)

Warasarn Manusysart Parithat. 27:

63-67.

Pongudom, Ratchanin. 2005. The Relationship

between Language and Values on

Beauty: A Study of Advertising

Discourse on Cosmetics in Thai.

Master's thesis, Chulalongkorn

University, Bangkok, Thailand.

Prompapakorn, Praparat. 2005. Dialect

Contact and New Dialect Formation

in a Thai New Town. Doctoral

dissertation, University of Essex,

Colchester, United Kingdom.

Rangkupan, Suda. 2005. A System of

Epistemic Modality in Thai. Manusya:

Journal of Humanities 8.1: 51-67.

Rangpongsumrit, Nunghatai. 2005.

Morphological and Analytic

Causatives in Spanish: A Syntactico-

Semantic Study. Doctoral Dissertation,
Chulalongkorn University, Bangkok, Thailand.

Ruangjaroon, Sugunya. 2005. The Syntax of Wh-Expressions as Varibles in Thai.

Doctoral dissertation, The University of British Columbia, Vancouver,

Canada.

Sittirak, Nantana et al. 2005. An Analytical

Study of Soccer News Translatior in

the Star's Soccer Daily Newspaper.

Sonklanakarin: Journal of Social

Sciences and Humanities Division of

Academic Affairs, PSU 11.2: 209-

232.

Sookgasem, Prapa (1990). Morphology,

Semantics, and Syntax of Auxiliaries

in Thai. Doctoral dissertation, the

University of Arizona, Tuscon.

Srinarawat, Deeyu. 2005. Indirectness as a

Politeness Strategy of Thai Speakers.

In Broading the Horizon of

Linguistic Politeness, ed. by Robin

Tolmach Lakoff, and Sachiko Ide,

pp. 175-193. Amsterdam: John

Benjamins.

Suaysod, Chuliporn. 2005. The English

Code-Mixing in Thai Speech of the

Secondary School Students: The

Case Study of the Students in

Mattayomsuksa 3 and 6 of

Nawaminthrachinuthit Suankularb 
Wattayalai School in Pathumthani.

Master's thesis, Kasetsart University, Bangkok, Thailand.

*Sudmuk, Cholthicha. 2005. The Syntax and

Semantics of Serial Verb

Constructions in Thai. Doctoral

dissertation, University of Texas,

Austin.

Sukmuen, Nuannapha. 2005. Slang from

Linguistic Angle. Chulasarn Thai,

Special Issue. 43-49.

Suraratdecha, Sumittra. 2005. Thai-English

Codeswitching: A Hawai'i Case

Study. Doctoral dissertation,

University of Hawai'i, Manoa.

Tansiri, Kachen. 2005. Interactions Between

Grammatical Aspect and Lexical

Aspect: A Case Study of Alternating

Intransitive Constructions in Thai.

Master's thesis, Chulalongkorn

University, Bangkok, Thailand.

Teeranon, Phanintra. 2005. Fundamental

Frequency Behavior of Vowels

Influenced by Phonetic Contexts in

Waic Languages: Implications for

Tonogenesis Theories. Doctoral

dissertation, Chulalongkorn University,

Bangkok, Thailand.

Tepnarong, Kittiwan. 2005. Linguistic

Features of and Attitudes towards

Language Used in Political
Headlines in Thai Daily Newspapers.

Master's thesis, Thammasat

University, Bangkok, Thailand.

Thima, Namthip. 2005. A Comparative Study of Old-Style and Modern Thai

Riddles. Master's thesis, Thammasat

University, Bangkok, Thailand.

*Timyam, Napasri. 2005. The Interaction of Linguistic, Pragmatic, and Social Factors: The Case of Datives and Ditransitives in Thai. Doctoral dissertation, University of Hawai'i, Manoa.

Todd, Richard Watson. 2005. A Fuzzy

Approach to Discourse Topics.

Semiotica. 155.1-4 :93-123.

Tuaycharoen, Pintip. 2005. Khwam

Kiawnueng Rawaang Naj Thaang

Khwaammaaj Kap Saphaawa Radap

Lotlan Khong Sara Naj Khamkhuu

Phasaa Isaan. (Relation between

Vowel Gradation and Semantic

Implication in Isaan Dialect

Doublets). Journal of Language and

linguistics .Thammasat University.

24.1: 59-75.

Ukosakul, Margaret. 2005. The Significance

of "Face" and Politeness in Social

Interaction as Revealed through Thai

"Face" Idioms. In Broading the

Horizon of Linguistic Politeness, ed. 
By Robin Tolmach Lakoff, and

Sachiko Ide, pp. 117-125. Amsterdam:

John Benjamins.

Worapong, Kantipa. 2005. Language Used on the Webboard by Students in Secondary Schools. Master's thesis, Kasetsart University, Bangkok, Thailand.

Yimsen, Prachuab, 2005. Kaan Sadeang Khwaam Suphaap Naj Phaasa Kawlii (Politeness in Korean). Journal of Humanities \& Social Sciences, PSU 1.1: 36-45

*Indicates a thesis or a dissertation not available at the time of study. 